\title{
Use of respiration rates of scyphozoan jellyfish to estimate their effects on the food web
}

\author{
Jennifer E. Purcell • Verónica Fuentes • \\ Dacha Atienza $\cdot$ Uxue Tilves · Diana Astorga • \\ Masato Kawahara • Graeme C. Hays
}

Published online: 9 April 2010

(C) The Author(s) 2010. This article is published with open access at Springerlink.com

\begin{abstract}
One of the main objectives of research on jellyfish is to determine their effects on the food web. They are voracious consumers that have similar diets to those of zooplanktivorous fish, as well as eating microplankton and ichthyoplankton. Respiration rates (RRs) can be used to estimate the amount of food needed to balance metabolism, and thereby estimate minimum ingestion. We compiled RRs for scyphozoan medusae in three suborders (Semeaostomeae, Rhizostomeae, and Coronatae) to determine if a single regression could relate $\mathrm{RRs}$ to mass for diverse scyphomedusan species. Temperature $\left(7-30^{\circ} \mathrm{C}\right)$ was not a significant factor. RRs versus wet weight (WW) regressions differed significantly for semeaostome and rhizostome medusae; however, RRs versus carbon
\end{abstract}

Guest editors: J. E. Purcell \& Dror Angel / Jellyfish Blooms: New Problems and Solutions

J. E. Purcell ( $\square)$

Shannon Point Marine Center, Western Washington

University, 1900 Shannon Point Rd, Anacortes,

WA 98221, USA

e-mail: purcelj3@wwu.edu

\section{J. E. Purcell}

Coastal and Marine Resources Centre, University College Cork, Naval Base, Haulbowline Island, Cobh, Co. Cork, Ireland

V. Fuentes · D. Atienza - U. Tilves

Institut de Ciencies del Mar, CSIC, P. Marítim de la

Barcelona 37-49, 08003 Barcelona, Spain mass over five-orders of magnitude did not differ significantly among suborders. RRs were isometric against medusa carbon mass, with data for all species scaling to the power 0.94 . The scyphomedusa respiration rate (SRR) regression enables estimation of $\mathrm{RR}$ for any scyphomedusa from its carbon mass. The error of the SRR regression was $\pm 72 \%$, which is small in comparison with the 1,000-fold variation in field sampling. This predictive equation ( $\mathrm{RR}$ in $\mathrm{ml} \mathrm{O}_{2}$ $\mathrm{d}^{-1}=83.37 * \mathrm{~g} \mathrm{C}^{0.940}$ ) can be used to estimate minimum ingestion by scyphomedusae without exhaustive collection of feeding data. In addition, effects of confinement on RRs during incubation of medusae were tested. Large medusae incubated in small container volumes $(\mathrm{CV})$ relative to their size (ratios of CV:WW < 50) had RRs one-tenth those of medusae in relatively larger containers. Depleted oxygen during incubation did not depress RRs of the

D. Astorga

Instituto de Ciencias Marinas de Andalucía, CSIC, Avda. República, Saharaui no 2, 11519 Puerto Real, Cádiz, Spain

\footnotetext{
M. Kawahara

Graduate School of Biosphere Sciences, Hiroshima

University, 4-4, Kagamiyama 1 Chome,

Higashi-Hiroshima 739-8528, Japan

G. C. Hays

Department of Pure and Applied Ecology, Institute of Environmental Sustainability, Swansea University, Swansea SA2 8PP, UK
} 
medusae; however, swimming may have been restricted and respiration reduced in consequence. We briefly review other problems with RR experiments and suggest protocols and limitations for estimating ingestion rates of jellyfish from metabolic rates.

Keywords Jellyfish - Metabolism - Zooplankton · Methods · Review · Aurelia $\cdot$ Rhizostoma $\cdot$ ETS

\section{Introduction}

Reports of jellyfish blooms are increasing worldwide (reviewed in Purcell et al., 2007). These blooms often cause problems for humans and economic damage to various industries such as fishing, aquaculture, power production, and tourism. The possibility that jellyfish populations are increasing has lead to much speculation about the causes. It also has emphasized how little is known about jellyfish populations globally. Thus, there is an urgent need for research on jellyfish.

Purcell (2009) advocates large-scale methods in order to address this global issue. In addition to determination of the species and biomasses of jellyfish populations, their effects on ecosystems need to be evaluated. Recognition of similar feeding and physiological characteristics among species can facilitate prediction of jellyfish ecosystem effects in disparate habitats. For example, the feeding rates of four scyphozoan species, Aurelia aurita (Linnaeus), Aurelia labiata Chamisso \& Eysenhardt, Cyanea capillata (Linnaeus), and Chrysaora quinquecirrha (Desor) increased significantly with body mass and prey density, but not temperature (Purcell, 2009). Respiration rates (RRs) of those species increased with body mass (slope $=0.936$ ), but not temperature (Purcell, 2009). Glazier (2006) reviewed metabolic rates of pelagic animals, including jellyfish, which scaled isometrically (1:1) with mass, in contrast to the 3/4-power scaling rule commonly accepted for benthic animals and vertebrates (Nagy et al., 1999; Nagy, 2005).

The amounts of prey consumed by jellyfish in situ have been estimated from clearance rate experiments in the laboratory (CR), gut content analysis of field specimens with digestion times measured in the laboratory (GCDT), and RR experiments [reviewed in Purcell (1997)]. Each of these methods has disadvantages. CR experiments are fraught with artifacts that compromise the results, including confinement that detrimentally affects the behaviors of the predator and prey, and unnatural prey at extreme densities; usually, rates are underestimated. GCDT studies minimize those artifacts, but are very timeconsuming, and are situation-specific. RR experiments presumably minimize laboratory artifacts and are relatively easy to conduct.

Use of RRs to estimate jellyfish energetic requirements also has disadvantages. Differences in RR experimental protocols may affect the results, as common to laboratory studies on jellyfish and zooplankton (ICES, 2000): (1) treatment of temperature differs among experiments, which may be conducted at ambient water temperature or changed quickly to determine a $\mathrm{Q}_{10}$; (2) the amount of food preceding $\mathrm{RR}$ incubations ranges from starved to field-collected to heavily fed. The measured rates usually underestimate actual consumption because specimens have been starved for different durations (hours to days) in order to measure a 'basal' or 'standard' rate and growth and reproductive costs generally are not included; and (3) confinement in the incubation containers could depress RRs in two ways: available oxygen could be depleted sufficiently during incubation to lower measured rates, or swimming could be restricted.

The problems with conditions in RR experiments have been addressed previously, to some degree. For example, (1) RRs measured at near-ambient temperatures did not increase with temperature according to $\mathrm{Q}_{10}$ predictions; near-ambient temperatures did not significantly affect the RR equation of the four species examined (Purcell, 2009); (2) it has been demonstrated repeatedly that feeding increases RRs (e.g., Møller \& Riisgård, 2007); (3) the possible effects of confinement on RRs, however, have not been examined for jellyfish, to our knowledge. Effects of confinement on feeding rates of jellyfish are well documented (reviewed in Purcell, 1997, 2009). Rhizostome, coronate, and cubozoan medusae, in particular, are vigorous swimmers (e.g., Larson, 1991, 1992; D'Ambra et al., 2001; Gordon \& Seymour, 2009; Klevjer et al., 2009). Therefore, restriction of swimming in containers could reduce activity and RRs.

The objectives of this study were twofold. First, to determine if RRs of other scyphozoan species fit the equation derived from four species in Purcell (2009), 
we used published RRs of scyphomedusae and new data for Rhizostoma pulmo (Macri) and Nemopilema nomurai (Kishinouye) to calculate a predictive regression. Second, to determine if incubation of medusae in small containers relative to their size lowered the measured RRs, we compared RRs of medusae versus the container volume. Then, to evaluate possible causes of reduced RRs in small containers, we tested whether available oxygen was reduced sufficiently to lower RRs. We discuss evidence that swimming, and hence RRs, may be reduced by confinement.

\section{Materials and methods}

Regression analyses of scyphomedusa respiration rates

We tested if RRs can be predicted across scyphomedusan species by regression of medusa mass vs. RR measured at ambient temperatures. We used data previously analyzed in Purcell (2009) for the scyphomedusae A. aurita, A. labiata, C. quinquecirrha, and $C$. capillata (Suborder Semeaostomeae) (Table 1). In the present analysis, we include additional data for A. aurita, three other semeaostome species, four species in Suborder Rhizostomeae, and two species in Suborder Coronatae (Tables 1, 2). No RRs were found for cubozoan medusae. In two studies (Nemazie et al., 1993; Pitt et al., 2005), metabolism was measured as excretion rates, which we converted to RRs by the O:N atomic ratio of 11.6 (Purcell \& Kremer, 1983). RRs were standardized to $\mathrm{ml} \mathrm{O}_{2}$ medusa $^{-1} \mathrm{~d}^{-1}$ by the conversions $1 \mathrm{ml} \mathrm{O} \mathrm{O}_{2}=$ $1.42 \mathrm{mg} \mathrm{O}_{2}=44.88 \mu \mathrm{mol} \quad \mathrm{O}_{2}=89.76 \mu \mathrm{g}$ atoms $\mathrm{O}_{2}$. Conditions of the experiments, i.e., temperature $\left({ }^{\circ} \mathrm{C}\right)$, time without food, ranges of medusa wet weight (WW), and incubation container volume (CV) are in Table 2. Medusa mass was standardized to WW and carbon (C) by published conversions in the same study or from the most-similar species; few carbon contents for rhizostome medusa exist (Table 3).

Previously unpublished RR data also are presented for some species. R. pulmo medusae were cultured from polyps in the laboratory of the Institut de Ciencies del Mar in Barcelona, Spain. Before the experiments, medusae were maintained in kreisels with natural seawater at $20^{\circ} \mathrm{C}$ and fed with Artemia sp. nauplii daily. RRs of small medusae were measured in acid-washed jars filled with 5- $\mu \mathrm{m}$ filtered natural seawater and sealed with Parafilm ${ }^{\odot}$ under the jar lid. Each jar contained one medusa or only filtered water (controls). After 4-7 h incubation, 50-ml subsamples were transferred without mixing into glass-stoppered bottles. Dissolved oxygen concentrations ([DO]) were measured by Winkler titration (Strickland \& Parsons, 1972) with a Mettler Toledo DL50 Graphix Titrator. After incubation, bell diameter $(\mathrm{mm})$ of each medusa was measured. Wet weights of some specimens were measured $\pm 1 \mu \mathrm{g}$ on a Mettler Toledo Balance MX5. Those specimens then were dried at $60^{\circ} \mathrm{C}$ until the weight stabilized (average of $4 \mathrm{~d}$ ) and dry weight (DW) measured as above. Carbon (C) and nitrogen (N) contents were measured with a $\mathrm{CHN}$ analyzer. Regression of diameter to $\mathrm{WW}$, and the percentages of DW in WW (DW\%WW) and of DW in C (C\%DW) enabled conversions among size units (Table 3).

RRs of $A$. aurita medusae collected from the Northern Adriatic Sea were measured at the Marine Biology Station in Piran, Slovenia at $16^{\circ} \mathrm{C}, 38$ salinity, and dim light (Garcia, data). After 1-h acclimation, medusae were incubated individually in glass containers with 2.51 of $0.2-\mu \mathrm{m}$-filtered seawater. RRs of R. pulmo collected from the Mar Menor coastal saline lagoon (western Mediterranean) were measured at Universidad de Alicante, Spain at $24.6-27^{\circ} \mathrm{C}$, 45-48 salinity, and dim light. After 3 -h acclimation, medusae were incubated individually in glass containers with 9-12 1 of $0.2-\mu \mathrm{m}$-filtered seawater at ambient temperature and salinity. For both species, identical containers without medusae were used as controls. The jars were sealed with parafilm and incubated $4 \mathrm{~h}$ in a thermostatic chamber. Before and after incubation, 125-ml subsamples were transferred without mixing into glass-stoppered bottles. [DO] was measured by Winkler titration using a Metrohm 794 Titoprocessor. Bell diameter and WW of all medusae were measured after incubation.

RRs of small $N$. nomurai were measured at the Graduate School of Biosphere Sciences, Hiroshima University, Hiroshima, Japan. Ephyrae liberated from polyps were cultured in 18-1 kreisel tanks at $24 \pm 1^{\circ} \mathrm{C}$ and fed Artemia sp. twice daily. Individual medusae first were placed in 500-ml beakers with filtered (Whatman GF/F) seawater for $3 \mathrm{~h}$, and then incubated in 500-ml airtight glass bottles with filtered seawater for $3 \mathrm{~h}$ in darkness. Large $N$. nomurai were 


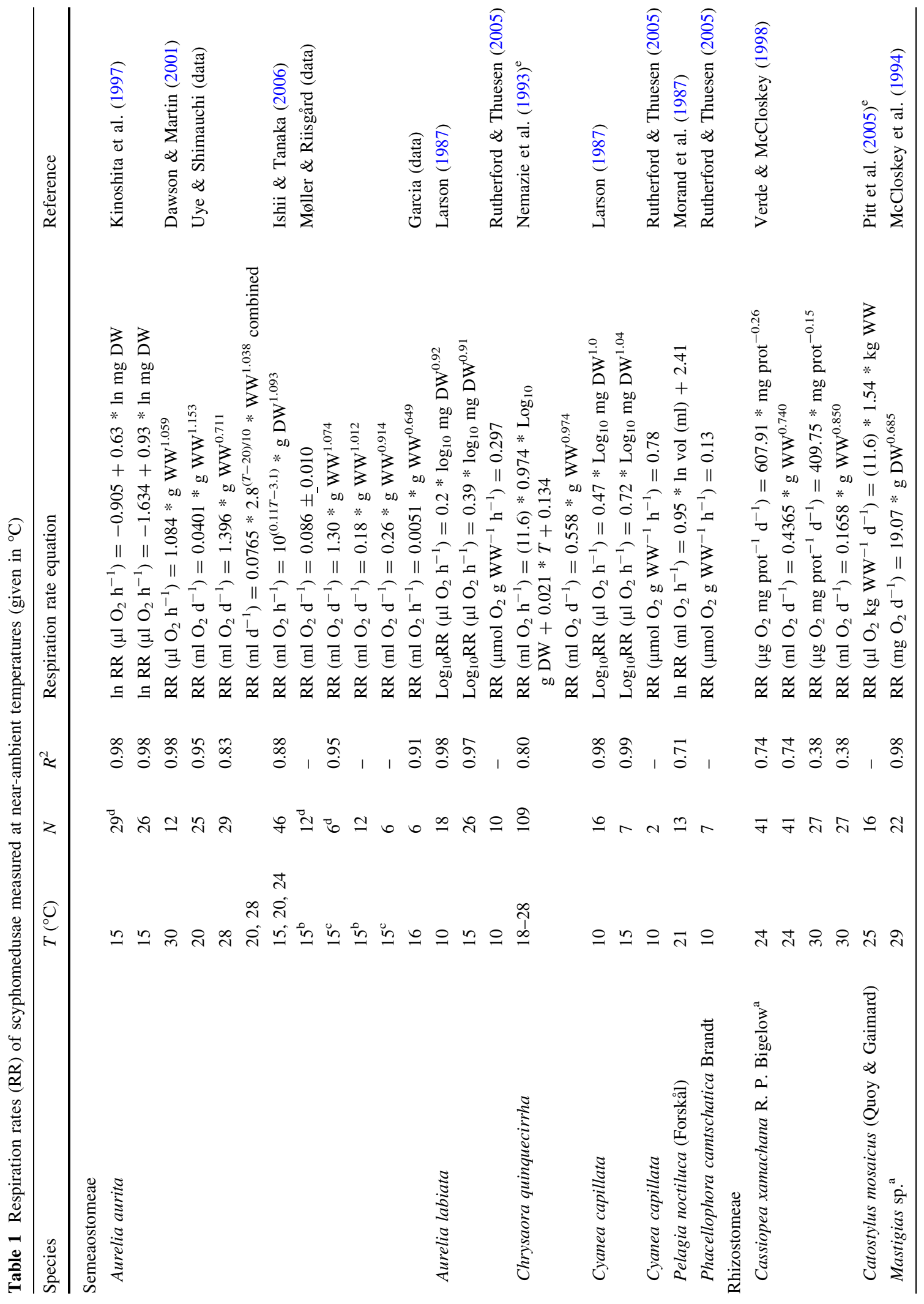




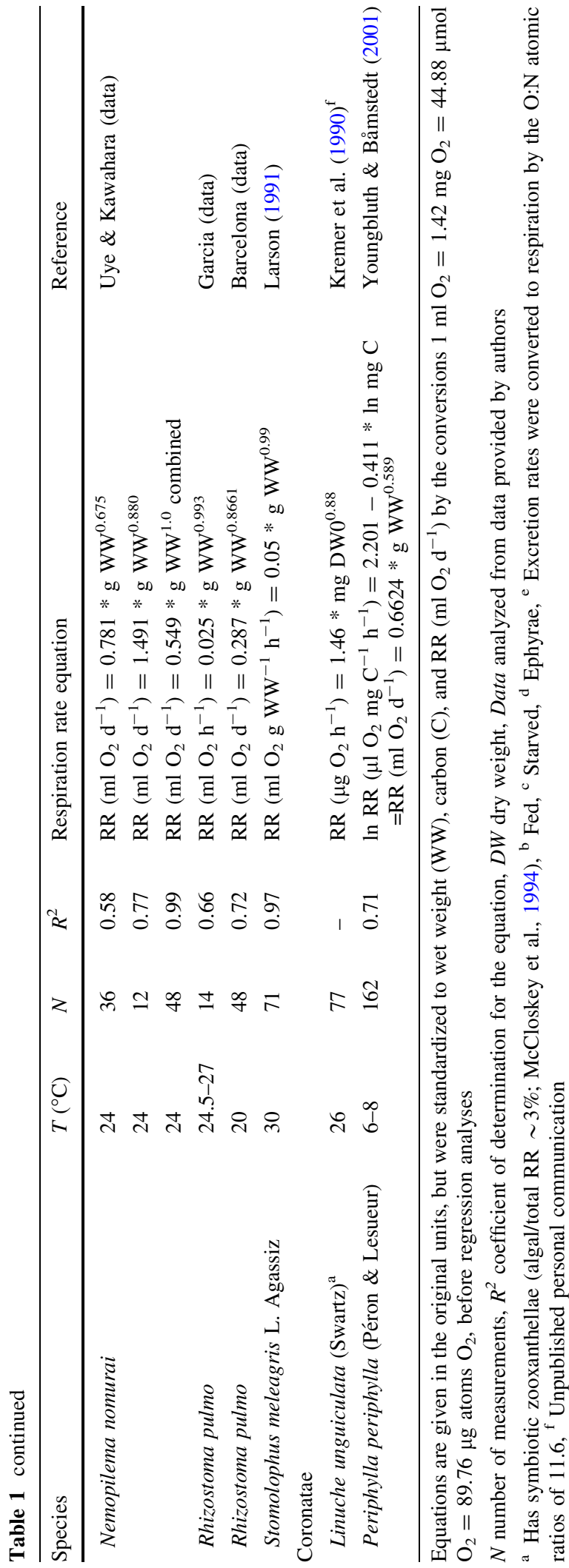

collected by a scoop net around Tsushima Island, Japan. The medusae immediately were transferred into a 2000-1 plastic tank containing $10-\mu \mathrm{m}$-filtered seawater for 3-5 h. Each medusa was immersed twice for $10 \mathrm{~min}$ in a 50-1 tank filled with filtered seawater and then incubated in an 80-1 airtight tank with filtered seawater at ambient temperature $\left(24 \pm 1{ }^{\circ} \mathrm{C}\right.$ ) and salinity (34) for 40 to $100 \mathrm{~min}$ in the shade. [DO] at the beginning and end of the experiments was measured by the Winkler method. Bell diameter and WW of all medusae were measured after incubation. Large medusae were dried at $60^{\circ} \mathrm{C}$ until the weight stabilized (average $4 \mathrm{~d}$ ) and DW measured. $\mathrm{C}$ and $\mathrm{N}$ contents were measured with a Yanako MT-5 CHN analyzer.

For regression analyses, RR was regressed against WW in each of the unpublished data sets (Table 1). Next, we calculated one RR each at the minimum and maximum sizes at each experimental temperature from regressions in each study in Table 1 . We $\log _{10^{-}}$ transformed RR and mass data prior to analysis. Although temperature was not a significant factor in the earlier analysis (Purcell, 2009), we first tested for effects of temperature and mass on medusa RRs in a multiple regression. Then, the log-transformed scyphomedusan $\mathrm{RR}\left(\mathrm{ml} \mathrm{O}_{2}\right.$ medusa $\left.^{-1} \mathrm{~d}^{-1}\right)$ data were regressed against medusa mass in WW $(\mathrm{g})$ and in $\mathrm{C}$ ( $g$ ) in simple linear regressions. We then tested for differences between the regressions (RR vs. WW and RR vs. C) for semeaostomes and rhizostomes with analysis of covariance (ANCOVA). Data transformations and regression analyses were made with SigmaStat $^{\odot} 3.5$ software, and ANCOVAs were done with Minitab 8.2 Extended software.

\section{Container effects on scyphomedusa respiration} rates

First, we tested the relationships of medusa WW, RR, and container volume (CV), using only the minimum and maximum WWs, RRs, and CVs for each study and temperature (Table 2; Fig. 1). Because often ranges were given for $\mathrm{CV}$ and $\mathrm{WW}$, we assumed that the smallest and largest medusae were incubated in the smallest and largest containers, respectively. We $\log _{10}$-transformed $\mathrm{RR}, \mathrm{WW}$, and $\mathrm{CV}$ data prior to analysis with Pearson product moment correlation to determine if WWs, RRs, and CVs were co-correlated using SigmaStat ${ }^{\odot} 3.5$ software. 


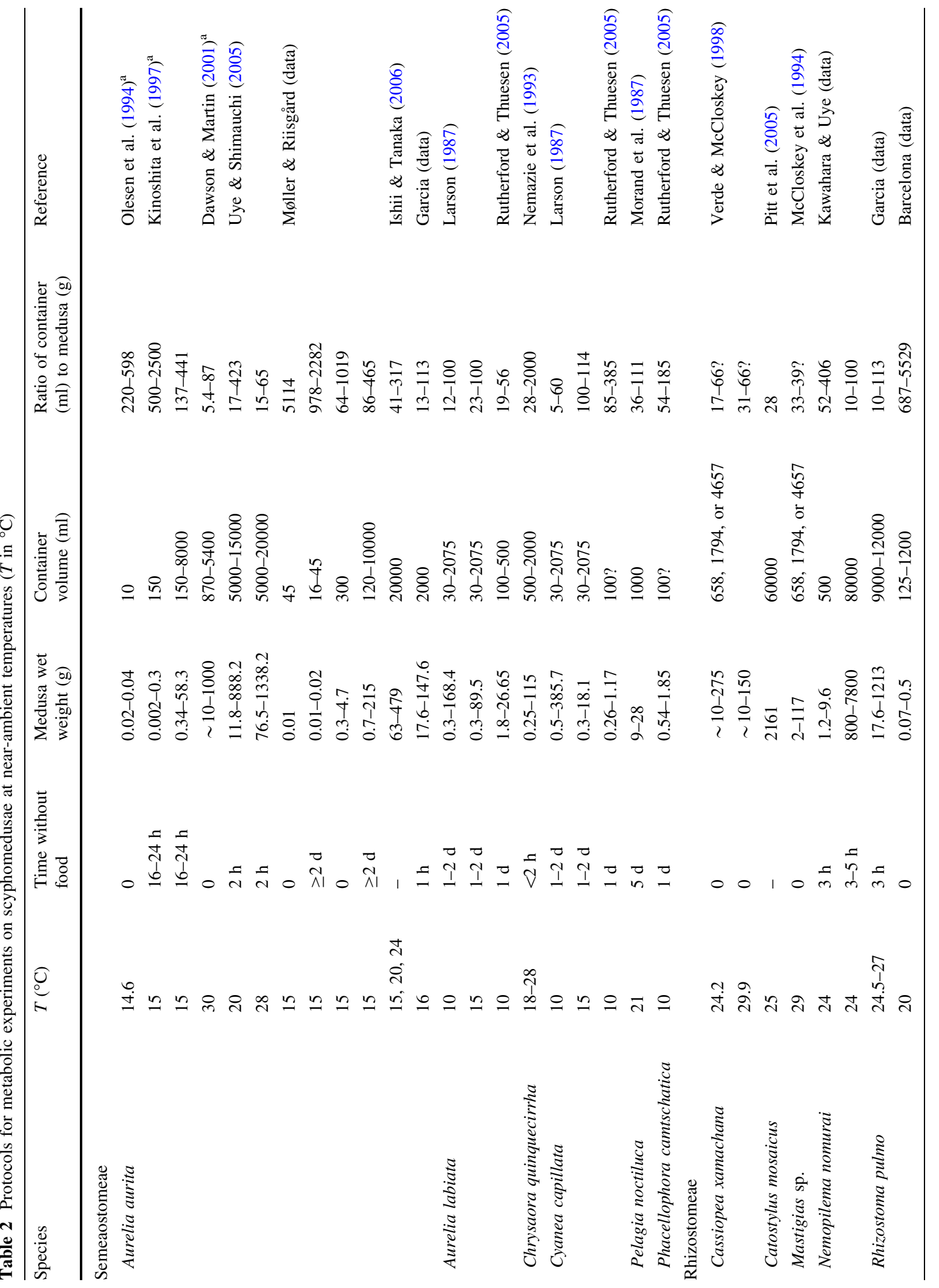


Next, we examined size-specific RRs versus the ratios of $\mathrm{CV}$ to medusa $\mathrm{WW}$ to determine if $\mathrm{CV}$ affected RRs (Table 2). Minimum and maximum $\mathrm{CVs}$ (ml) were divided by minimum and maximum medusa WWs (g) to yield a range of ratios of $\mathrm{CV}$ to WW (CV:WW ratio) for each study. CV for studies of McCloskey et al. (1994) and Verde \& McCloskey (1998) were in McCloskey et al. (1985). Data on WW, CV, and RR were kindly provided by the authors of previous publications, specifically, Uye \& Shimauchi (2005), Møller \& Riisgård (2007), and Uye (2008). For those data and our unpublished data, carbon-specific RRs of individual medusae were compared with their CV:WW ratios.

We tested if [DO] was substantially depleted during incubation. We used data on $\mathrm{CV}$, incubation time, temperature $\left({ }^{\circ} \mathrm{C}\right)$, and $\mathrm{RR}$ to calculate the percentage $(\%)$ reduction of DO during incubation. Because we lacked initial [DO] in all but two studies, we assumed that incubation water was saturated at the start of each experiment. Saturation [DO] (in $\mathrm{mg}^{-1}$; calculated from www.hbuehrer.ch/Rechner/ O2satur.html, accessed 18 July 2009) were converted to $\mathrm{ml}^{-1}$ and multiplied by container volume (=available DO). RRs of medusae (Table 1) were multiplied by CVs and divided by the available DO to estimate \% DO depletion.

Data are presented as ranges and mean \pm standard error. The numbers of measurements (equal to the number of specimens except when multiple medusae were incubated in a container) are in Table 1.

\section{Results}

Regression analyses of scyphomedusan respiration rates

Multiple linear regression of log-transformed scyphomedusan RR $\left(\mathrm{ml} \mathrm{O}_{2}\right.$ medusa $\left.^{-1} \mathrm{~d}^{-1}\right)$ data showed that medusa mass $\left(t_{2,47}=26.1, P<0.001\right)$, but not temperature $\left(t_{2}, 47=1.0, P=0.332\right)$ significantly affected RRs; therefore, temperature was not considered further in the analyses.

When medusa mass was expressed as wet weight (WW), both WW and suborder (Semeaostomeae vs. Rhizostomeae) significantly influenced RR (ANCOVA: effect of $\log _{10} \mathrm{WW}, F_{1,46}=366.9, P<0.001$; effect of suborder, $\left.F_{1,46}=18.9, P<0.001\right)$. The slopes of both 
Table 3 Biometric conversions for scyphomedusae, with ambient salinities

\begin{tabular}{|c|c|c|c|c|c|}
\hline Species & DW\%WW & C\%DW & $\mathrm{C} \% \mathrm{WW}$ & Salinity & Reference \\
\hline Aurelia aurita & 3.6 & 3.7 & 0.133 & $>30$ & Uye \& Shimauchi (2005) \\
\hline Aurelia labiata & 3.8 & 4.3 & 0.16 & $28-30$ & Larson (1986) \\
\hline Cyanea capillata & 4.2 & 12.8 & 0.55 & $28-30$ & Larson (1986) \\
\hline Chrysaora quinquecirrha & 1.8 & 11.1 & 0.19 & $6-12$ & Purcell (1992) \\
\hline \multirow[t]{2}{*}{ Chrysaora fuscescens Brandt } & $3.33^{\mathrm{a}}$ & $6.07^{\mathrm{a}}$ & $0.20^{\mathrm{a}}$ & $31-33$ & Shenker (1985) \\
\hline & 3.62 & 7.74 & 0.28 & $31-33$ & \\
\hline Pelagia noctiluca & ND & 11.4 & ND & ND & Morand et al. (1987) \\
\hline Catostylus mosaicus & 9.67 & ND & ND & ND & Pitt et al. (2005) \\
\hline Nemopilema nomurai & ND & ND & 0.6 & ND & Kawahara \& Uye (data) \\
\hline $\begin{array}{l}\text { Phyllorhiza punctata von } \\
\text { Lendenfeld (no zooxanthellae) }\end{array}$ & 3.8 & 12 & 0.46 & $29-32.5$ & Graham et al. (2003) \\
\hline Rhizostoma pulmo & $6.3^{\mathrm{a}}$ & $5.6^{\mathrm{a}}$ & $0.34^{\mathrm{a}}$ & 38 & Barcelona (data) \\
\hline Stomolophus meleagris & 4.17 & ND & ND & ND & Larson (1987) \\
\hline Linuche unguiculata & 4.7 & 11.8 & 0.56 & $\sim 35$ & Kremer et al. (1990) \\
\hline Periphylla periphylla & 3.24 & 19.6 & 0.64 & 33.2 & Youngbluth \& Båmstedt (2001) \\
\hline
\end{tabular}

$D W$ dry weight, $W W$ wet weight, $C$ carbon, $N D$ no data

a immature medusae

regressions were $\sim 1$ (Fig. 1A). RRs of coronate medusae coincided with those of rhizostomes, except for the largest Periphylla periphylla, which may have been a consequence of confinement (below).

When medusa mass was expressed as carbon (C), RRs of species in the 3 suborders scaled together vs. mass with a slope $\sim 1$ (Fig. $1 \mathrm{~B}$; slope $=0.939$; $R^{2}=0.926$ ). Some data for A. aurita from Garcia (data) and Phacellophora camtschatica fell below the prediction lines (Fig. 1B). A few other data (Cassiopea xamachana, an upside-down-jellyfish, and the largest $P$. periphylla) were lower than others in their suborders. The points beyond the prediction limits were removed for re-analysis of the regression. The revised regression yielded a higher $R^{2}$ value and slope $\left(\mathrm{RR}\right.$ in $\mathrm{ml} \mathrm{O}_{2} \mathrm{~d}^{-1}=83.37 * \mathrm{~g} \mathrm{C}^{0.940} ; R^{2}=0.943$; $\left.\mathrm{F}_{1,1}=826.31 ; \quad P<0.001\right)$. ANCOVA analysis showed a strong effect of mass in $\mathrm{g} \mathrm{C}\left(F_{1,46}=720\right.$, $P<0.001)$, but no effect of suborder $\left(F_{1,46}=0.000\right.$, $P=0.98)$; thus a regression equation combining the suborders was justified.

Young medusae (ephyrae) may have higher RRs and different scaling than larger medusae (Kinoshita et al., 1997; Møller \& Riisgård, 2007). RRs for A. aurita ephyrae against mass (converted to by $\mathrm{C} \% \mathrm{DW}=7.1$; Schneider, 1988) were slightly above the $95 \%$ confidence interval, but within the prediction error of the SRR regression (Fig. 1B). When ephyrae were included in the SRR regression, it yielded a higher $R^{2}$ value but less-steep slope ( $\mathrm{RR}$ in $\mathrm{ml} \mathrm{O}_{2} \mathrm{~d}^{-1}=$ $83.37 * \mathrm{~g} \mathrm{C}^{0.919} ; R^{2}=0.953 ; F_{1,54}=1106.57 ; P<$ 0.001). Because RRs for ephyrae seldom have been measured (except Morand et al., 1987), they were not included in further analyses.

The reliability of predicting RRs is of key importance for use of the scyphomedusan respiration rate (SRR) regression. The Standard Error of the estimate was 0.294. We calculated the coefficient of variation from the ratios of the individual RRs calculated from the original equations (Table 1) to RRs calculated from individual carbon weights entered in the SRR regression. The means and standard deviations of those ratios then were calculated. The coefficient of variation $=$ standard deviation/mean $\times 100$; thus, the error of the SRR regression $=72.2 \%$.

We used respiration regressions that were not used to develop the SRR regression to test how well RRs of the same-sized medusae compared between their original regression and the SRR regression (Table 4). With the exception of large $C$. capillata medusae in Mangum et al. (1972), which were incubated in small containers $(\mathrm{CV}: \mathrm{WW}$ ratio $=20)$ and may have had depressed RRs, the SRR regression underestimated some original RRs by $2.1-37.5 \%$ and overestimated others by $27-67 \%$. 
Fig. 1 Log-log plots of scyphomedusan respiration rates $(\mathrm{RR})$ in $\mathrm{ml} \mathrm{O}_{2} \mathrm{~d}^{-1}$ measured at ambient temperatures versus mass from studies in Table 1. One point (mean) or two points (minimum and maximum mass) are plotted per study at each temperature. A RR versus wet weight (WW) in grams by suborder. Regression equations are:

semeaostomes

$\mathrm{RR}=6.054 * \mathrm{~g} \mathrm{WW}^{1.09}$; rhizostomes

$\mathrm{RR}=2.698 * \mathrm{~g} \mathrm{WW}^{0.917}$;

B RR versus carbon weight

(C) in grams by species.

Solid lines linear regression $\mathrm{RR}$ in $\mathrm{ml} \mathrm{O}_{2}$

$\mathrm{d}^{-1}=83.368 * \mathrm{~g} \mathrm{C}^{0.940}$, long dashes $95 \%$ confidence intervals, dotted lines prediction errors, short dashes semeaostome regression from Purcell (2009). Points below the prediction errors in $\mathbf{B}$ were omitted from $\mathbf{A}$
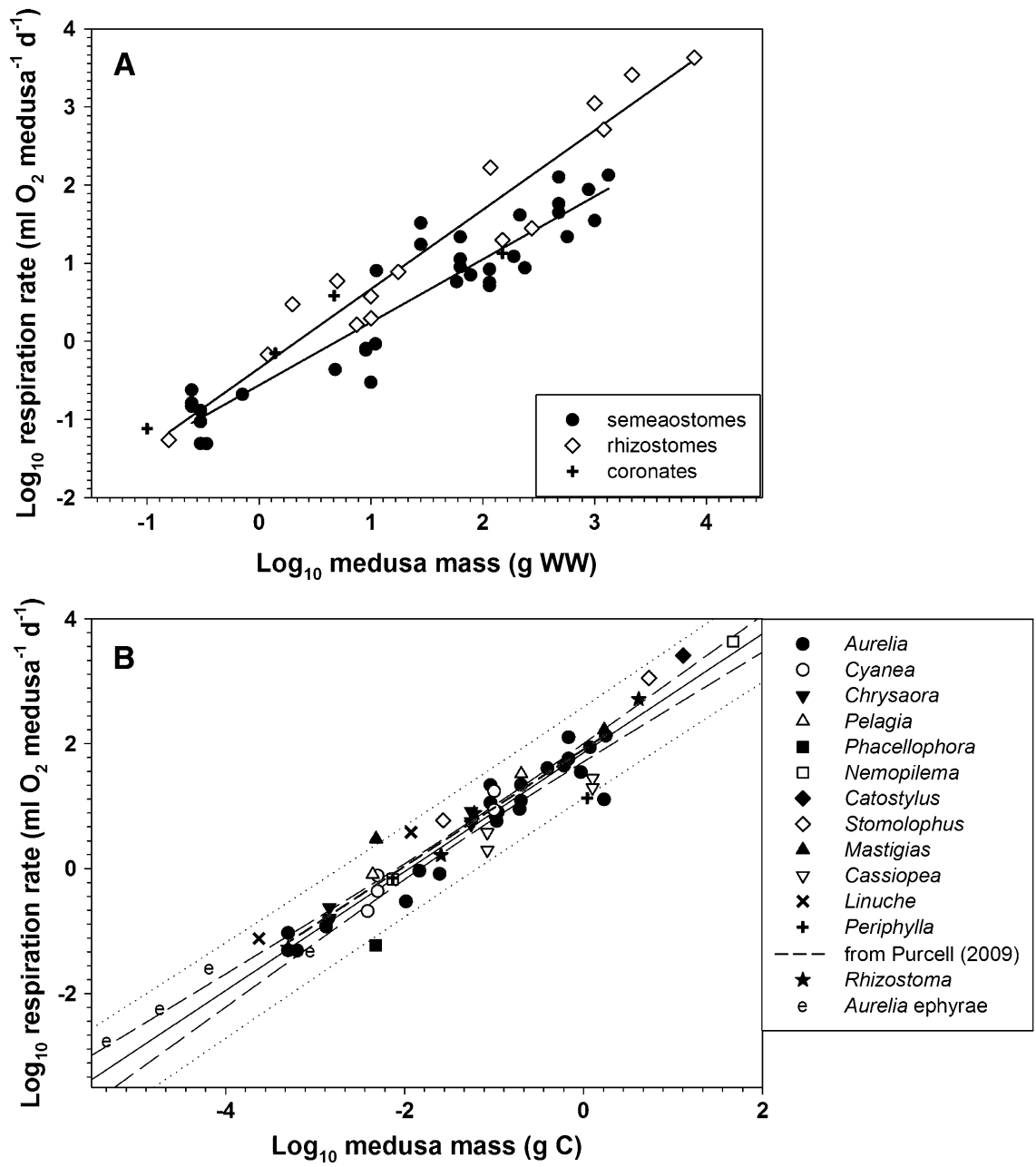

Container effects on scyphomedusa respiration rates

Medusa WWs were positively correlated with CVs (Fig. 2), which reflects selection of larger containers for larger specimens. All parameters (WW, RR, CV) were co-correlated (Table 5). Correlation of RR with WW is meaningful biologically; however, the positive correlation of RR with $\mathrm{CV}$ is not meaningful biologically and should be interpreted to result from increasing WW. The line for a constant ratio of $\mathrm{CV}$ to WW of 100:1 shows that most small medusae $(<10 \mathrm{~g}$ WW) were incubated in containers over 100 times their size $(1 \mathrm{ml}$ water weighs $1 \mathrm{~g})$. In contrast, most large medusae $(>10 \mathrm{~g} \mathrm{WW})$ were incubated in containers less than 100 times their size. This also is apparent from CV:WW ratios in Table 2.
Because RRs and CVs both were correlated with medusa WWs, we examined C-weight-specific RRs vs. the $\mathrm{CV}: \mathrm{WW}$ ratios from data on individual medusae. C-specific (C-sp) RRs were much higher in small medusae (top right of Fig. 3A), which generally were incubated in containers of greater relative volume than were large medusae. At $\mathrm{CV}$ :WW ratios less than $\sim 100: 1$, incubations of large A. aurita and R. pulmo medusae at low CV:WW ratios had much lower C-sp RRs (bottom left of Fig. 3A) than did those species at higher $\mathrm{CV}$ :WW ratios. Some of those data points were identified as low RRs previously in Fig. 1.

We examined data for individual medusae to determine if dissolved oxygen concentrations [DO] were depleted during incubation. A. aurita and $N$. nomurai medusae consumed $<1 \%$ of the DO 


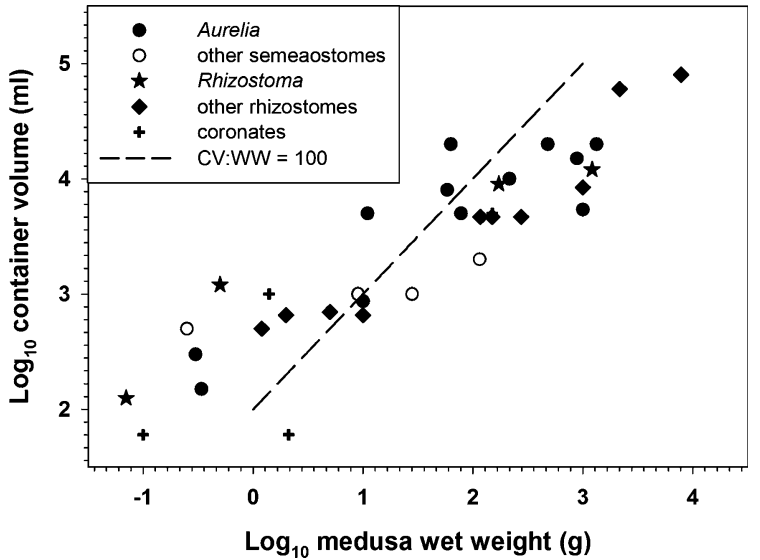

Fig. 2 Incubation-container volume (CV) vs. scyphomedusa wet weight $(\mathrm{WW})$. One point (mean) or two points (minimum and maximum mass) are plotted per study at each temperature. A CV:WW ratio $=100$ is shown by the dashed line
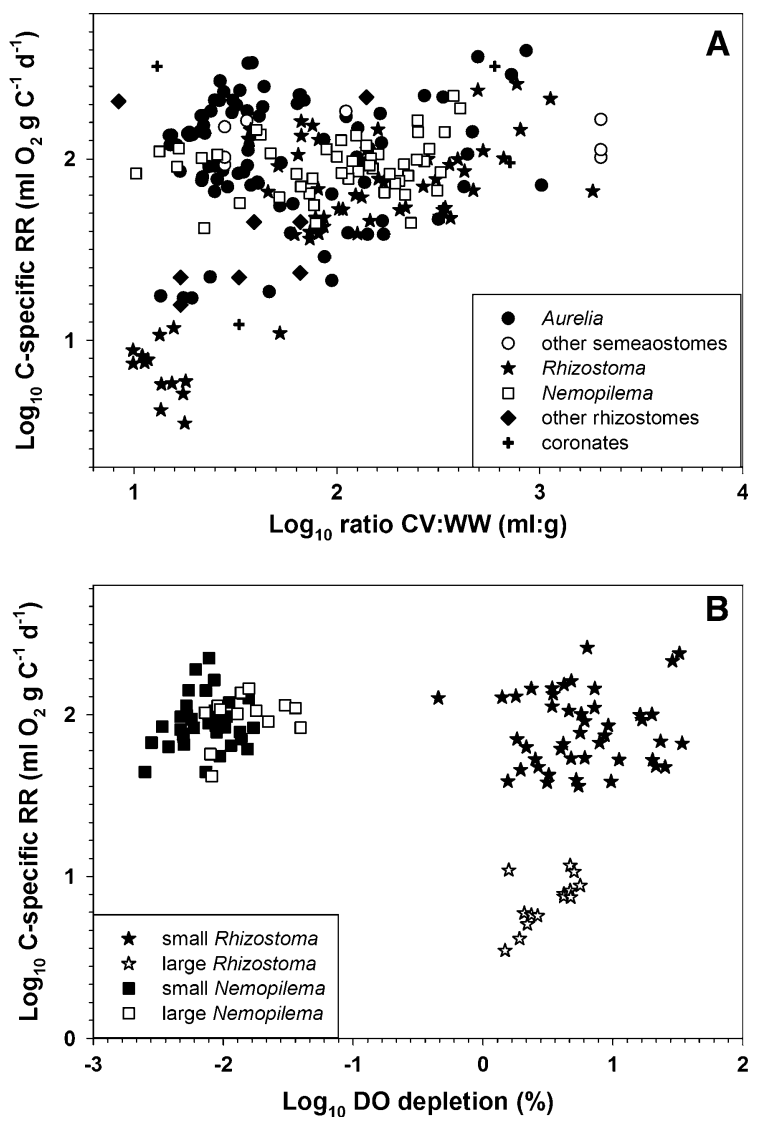

Fig. 3 Carbon-specific respiration rates of scyphomedusae vs. the ratios of container volume in $\mathrm{ml}$ to wet weight in grams $(\mathrm{CV}: \mathrm{WW})(\mathbf{A})$ and vs. the \% dissolved oxygen (DO) was depleted during incubation (B). Points are data for individual medusae from studies cited as (data) in Table 1 during incubation, and their C-sp RRs were consistent across the range of \% DO depletion (Fig. 3B). Small $(<5 \mathrm{~g}$ WW) $R$. pulmo depleted DO by $0.4-34.2 \%$ (mean $7.6 \pm 1.0 \%$ ) in experiments designed to test $\mathrm{CV}$ effects on RR, and their C-sp RRs were consistent across the range of \% DO depletion (Fig. 3B). Large (17.6-1213 g WW) $R$. pulmo depleted DO by $1.5-5.0 \%$ (mean $3.1 \pm 0.3 \%$ ), which was generally less than by small specimens; however, the C-sp RRs of large R. pulmo were an order of magnitude lower than of the small specimens (Fig. 3B). Small and large R. pulmo had significantly different \% DO depletion (one-way ANOVA, $\left.F_{1,57}=5.67, P=0.021\right)$ and C-sp RRs (one-way ANOVA, $F_{1,57}=260.47, P<0.001$ ).

Because RR regressions with slopes of considerably less than 1 (Table 1) suggested the possibility of depressed RRs of large medusae, we also examined $\%$ DO depletion in those experiments. Although the slopes of the RR regressions for small (0.675) and large (0.880) N. nomurai, A. aurita medusae at $28^{\circ} \mathrm{C}$ (0.717; Uye \& Shimauchi, data) and $16^{\circ} \mathrm{C}(0.646$, Garcia, data) were $<1, \%$ DO depletion was $<0.1 \%$. We lacked data for individual medusae of two other species, C. xamachana (0.74 and 0.85) and Mastigias sp. (0.675) that have symbiotic zooxanthellae; DO production from algal photosynthesis often exceeded DO consumption by medusae, and DO depletion was $<1 \%$. The RR slope of $P$. periphylla was 0.589 and DO depletion was $<0.03 \%$, assuming the longest incubation time $(13 \mathrm{~h})$. Thus, analysis of the [DO] changes in the incubation containers eliminated the possibility that low RRs might have resulted from depleted DO during incubation.

Although DO depletion could not explain depressed RRs in any of the above experiments, long incubation could otherwise detrimentally affect the health of the medusae. For $C$. xamachana $(24 \mathrm{~h})$, Mastigias sp. (24 h), and large P. Periphylla (13 h), long incubations could have contributed to depressing their RRs.

\section{Discussion}

Scaling of scyphomedusa respiration rates

Available data from 14 scyphozoan species in three suborders showed that RRs scaled with body mass ( $g$ C) over five-orders of magnitude. The SRR 


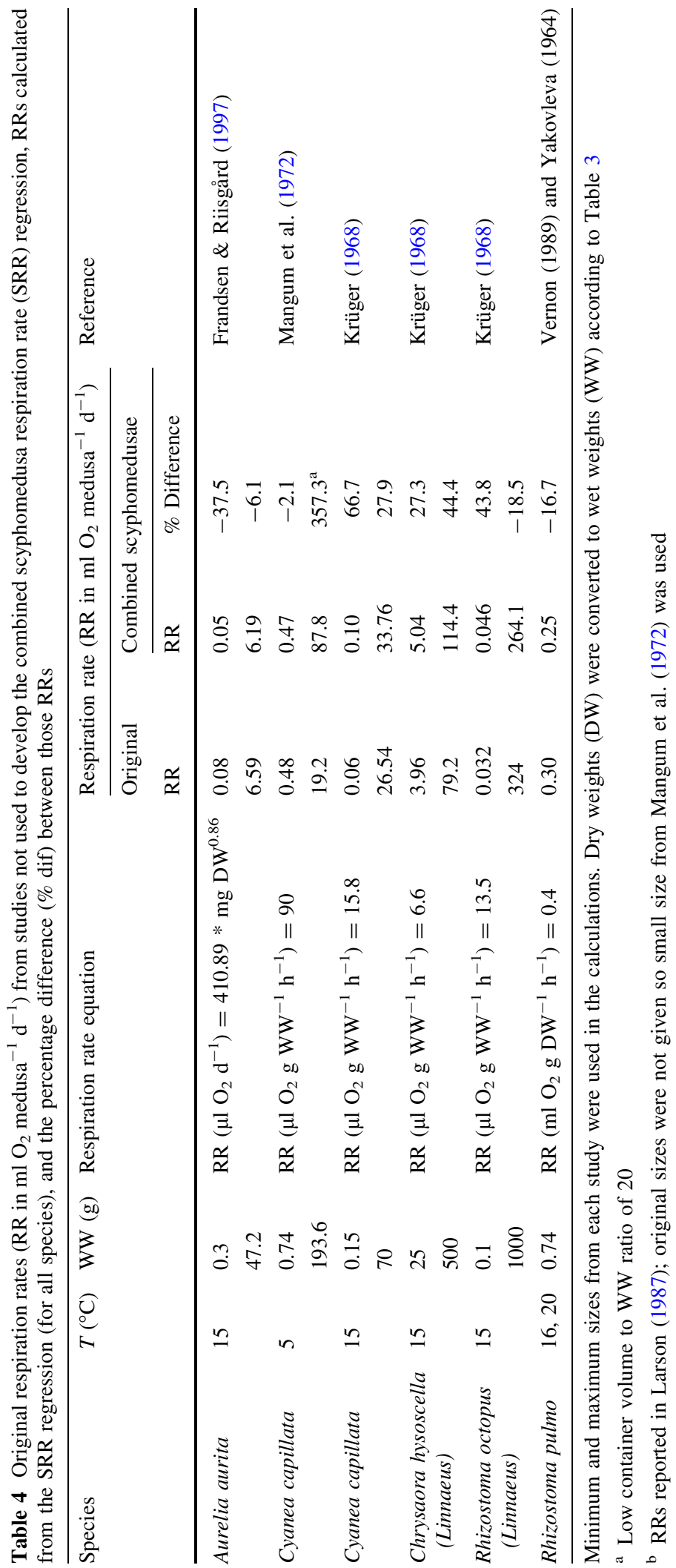


Table 5 Pearson Product Moment Correlations of container volume (CV in $\mathrm{ml}$ ), and scyphomedusa wet weight (WW in $\mathrm{g}$ ), with respiration rate $\left(\mathrm{RR}\right.$ in $\mathrm{ml} \mathrm{O}_{2}$ medusa ${ }^{-1} \mathrm{~d}^{-1}$ )

\begin{tabular}{lll}
\hline Pair of variables & \multicolumn{2}{l}{ Pearson's correlation } \\
\cline { 2 - 3 } & $R$ & $P$ \\
\hline RR vs. WW & 0.909 & $2.1 \times 10^{-21}$ \\
RR vs. CV & 0.820 & $1.8 \times 10^{-12}$ \\
WW vs. CV & 0.830 & $5.4 \times 10^{-13}$ \\
\hline
\end{tabular}

$R$ correlation coefficient, $P$ probability that the factors were not correlated. Data from Tables 1 and 2

regression may enable prediction of RRs of any scyphomedusan species from data only on body mass. As an example, we estimate ingestion from RRs and field size data for Chrysaora fuscescens medusae, for which metabolic data do not exist to our knowledge. Mean swimming bell diameter of medusae at Station 1 (17.4 cm: Suchman et al., 2008) was converted to $1.552 \mathrm{~g} \mathrm{C}$ from data in Shenker (1985) and entered into the SRR regression to yield $126 \mathrm{ml} \mathrm{O}_{2}$ consumed medusa ${ }^{-1} \mathrm{~d}^{-1}$. Multiplication by the RQ gives a minimum of $101 \mathrm{mg} \mathrm{C}$ consumed medusa ${ }^{-1} \mathrm{~d}^{-1}$ to balance respiration.

Scyphomedusae in three suborders scaled similarly with mass as wet weight ( $\mathrm{g} \mathrm{WW}$ ), but the RRs of the vigorously swimming rhizostome medusae generally were higher than RRs of semeaostomes. The carbon concentrations in the tissues of rhizostomes are higher than in semeaostomes and so the RRs vs. carbon mass of both suborders scaled together. Convenient measures of medusa size include swimming bell diameter and wet weight (WW), between which numerous conversions exist. Conversions to carbon (C) mass are available for several species, but few exist for rhizostome medusae (Table 3). One of the unavoidable approximations in our analysis was occasional use of WW and DW to $\mathrm{C}$ conversions from different species.

The slope of our predictive SRR regression (0.940) is similar to the previous regression for four semeaostome species (slope $=0.936$; Purcell, 2009), the regression lines being indistinguishable and nearly isometric (slope =1) (Fig. 1). The allometric exponents of $\sim 1$ for scyphomedusae concur with Glazier (2006), who concluded that RRs scaled with body mass of pelagic invertebrates with exponents of $\sim 1$. This differs from most benthic animals and vertebrates, which have allometric exponents closer to 0.75 (i.e., 'Kleiber's law'; Nagy et al., 1999). Several characteristics may explain isometric scaling in pelagic animals. Glazier (2006) speculates that their lack of change in body shape and surface area with age, their continued high production costs throughout life, and the energy required to maintain a suspended lifestyle, whether by swimming or buoyancy, could explain the high energy costs of isometric scaling in pelagic animals. RRs of the jellyfish, C. xamachana, had scaling exponents of 0.74 and 0.85 , which may reflect its epi-benthic lifestyle. We believe that container effects on large jellyfish could contribute to RR regressions with slopes considerably less than 1 in other species (discussed below).

For allometric equations of metabolic rates versus size in vertebrates, size is in live body mass (e.g., Nagy et al., 1999; Nagy, 2005), which would be WW for jellyfish; however, jellyfish have much higher water contents (95-98\%) than do fish (71-85\%; Doyle et al., 2007), making direct comparisons of the groups by live mass inequitable. For allometric equations of metabolic rates versus size of aquatic invertebrates, including zooplankton, size often is in DW, which is a poor choice for jellyfish because the residual salt in DWs differs with the salinity of the environment (Hirst \& Lucas, 1998), as illustrated by the very low DW\%WW of $C$. quinquecirrha medusae from salinities 6-12 as compared with other medusae at higher salinities (Table 3). Therefore, we recommend scaling by carbon mass for gelatinous zooplankton taxa.

Sources of error in RR experiments

\section{Temperature changes}

Purcell (2009) showed that RRs of 2 scyphomedusan and 1 ctenophore species did not increase with temperature as calculated from $\mathrm{Q}_{10} \mathrm{~s}$ derived from experiments in which temperatures were manipulated. Specifically, $\mathrm{Q}_{10} \mathrm{~S}$ at ambient temperatures were 1.67 for Aurelia spp. at $10-30^{\circ} \mathrm{C}$ and 1.6 for C. quinquecirrha at 18 to $28^{\circ} \mathrm{C}$, as compared with $\mathrm{Q}_{10} \mathrm{~S}$ of $\sim 3$ in manipulated-temperature experiments. $\mathrm{Q}_{10} \mathrm{~s}<2$ means that the animal is able to adjust its metabolic rate with temperature; temperature acclimation in medusae has been reported for a long time 
(Mangum et al., 1972). RRs used for the SRR regression were measured at ambient temperatures; however, temperature effects of season could have contributed to variability in the data. We conclude that RRs of scyphomedusae should not be adjusted for temperature by $\mathrm{Q}_{10} \mathrm{~S}$ determined from manipulated temperatures; metabolic rates should be measured at the ambient temperatures.

\section{Differences in prior feeding conditions}

Differences among experiments in terms of time without food and pre-feeding contribute to differences in RRs (discussed in Purcell, 2009). Preexperimental protocols differ from days unfed, use of newly collected specimens to reflect rates in situ, to feeding at high prey concentrations. A few studies explicitly tested the effects of food on RRs (e.g., Møller \& Riisgård, 2007); RRs of fed medusae decreased within $2.5 \mathrm{~h}$ to the rates of starved medusae. Differences in feeding regimes among the studies used in the present analyses probably contributed to variation in the data used here. Unnaturally, high food levels may increase RRs to levels higher than RRs in situ. We believe that for use of RRs for prey consumption estimates, the metabolic rates should be measured on newly collected specimens; however, that raises the issue of acclimation time, which we discuss below.

\section{Different acclimation and incubation times}

To our knowledge, no studies on medusae have evaluated how the durations of acclimation or incubation affect medusae in RR experiments. Often $1 \mathrm{~h}$ has been chosen arbitrarily for acclimation. The durations of incubation, from $<1-24 \mathrm{~h}$, have been compromises between sufficient time to detect differences in [DO] and not to deplete DO or stress the medusae. Differences in acclimation and incubation times among the studies used in the present analyses probably contributed to variability in the data. We suggest that experiments explicitly testing the effects of acclimation and incubation durations on RRs are needed. With improvements in oxygen electrodes, incubation times now can be shortened. We recommend that the durations of medusa confinement be minimized to minimize DO depletion and reduced health.

\section{Container volume effects}

We showed that container volume (CV) probably depressed RRs only of large medusae. Most prior studies, in which CV:WW ratios were $100-5,600$, yielded consistent C-sp RRs $\left(\sim 100 \mathrm{ml} \mathrm{O}_{2} \mathrm{~g} \mathrm{C}^{-1}\right.$ $\left.\mathrm{d}^{-1}\right)$. Evidence of depressed C-sp RRs $\left(\sim 10 \mathrm{ml} \mathrm{O}_{2} \mathrm{~g}\right.$ $\mathrm{C}^{-1} \mathrm{~d}^{-1}$ ) occurred with large medusae (A. aurita, C. capillata, $R$. pulmo, and $P$. periphylla) in containers $<50$ times larger than the medusa. We showed that depressed RRs probably did not result from depletion of the available DO, as might have occurred with low $\mathrm{CV}$ :WW ratios or long incubations.

We tested the validity of our assumption of saturated [DO] at the beginning of incubation with data for measured initial [DO]. The measured initial [DO] generally was higher than the calculated saturated [DO] (mean $112.3 \pm 2.2 \%$ ) for small $R$. pulmo (Barcelona, data). In contrast, initial [DO] was lower than saturated [DO] (mean $93.6 \pm 4.1 \%$ ) for large N. nomurai (Kawahara \& Uye, data). Nevertheless, the assumption of saturated [DO] gave reasonable estimates $( \pm 10 \%)$ of available DO at the beginning of the experiments. Depletion of DO is potentially a problem; large $N$. nomurai medusae had slowed swimming pulses at $<50 \%$ DO saturation (Kawahara, unpublished data).

Large animals usually have lower mass-specific RRs than do small animals (e.g., ICES, 2000). For example, C-sp RRs of ephyrae were 3.4 times those of small medusae (calculated from Kinoshita et al., 1997 and Møller \& Riisgård, data). Our analysis for medusae, however, suggests that low C-sp RRs of large medusae may be due in part to confinement effects. Obviously depressed RRs were seen at $\mathrm{CV}$ :WW ratios below 50, but less-obvious reductions may have occurred at higher ratios. The $\mathrm{C}$-sp RRs did not differ between small and large $N$. nomurai differing 100-1,000-fold in WW (Fig. 3), even though the $\mathrm{CV}$ :WW ratios were much greater for small (mean $184 \pm 16$ ) than for large medusae (mean $37 \pm 8$ ). That could be due to variation in the $\mathrm{CV}$ :WW ratios contributing to variation in the RRs.

Reduced activity in the containers is another probable cause of the low RRs. The best evidence for this is from Larson (1991), who showed higher RRs of active Stomolophus meleagris medusae as compared with inactive medusae with crushed rhopalia (Fig. 4). The relationships of S. meleagris RRs 


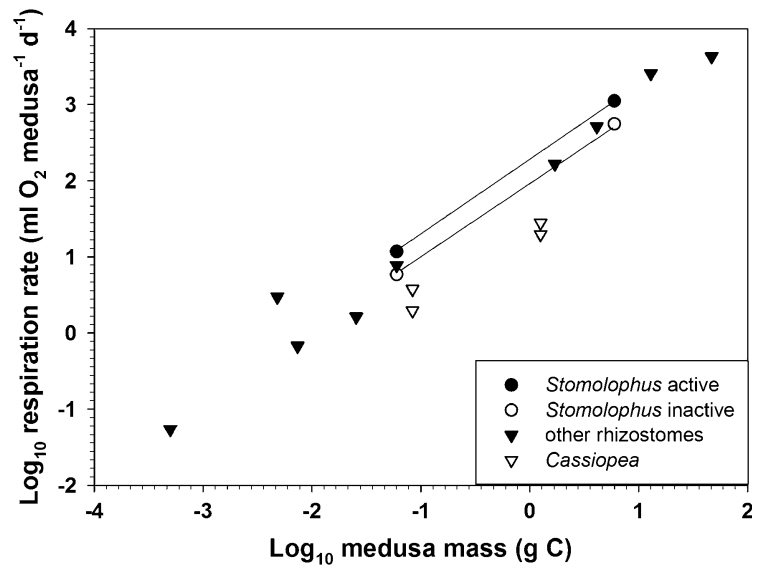

Fig. 4 Effect of activity on respiration rates vs. carbon (C) mass of rhizostome scyphomedusae. Stomolophus meleagris medusae were swimming (active) or had crushed rhopalia (inactive) from Larson (1991). Cassiopea xamachana medusae rest upside-down on the seabed. One point (mean) or two points (minimum and maximum mass) are plotted per study

versus carbon mass are consistent with other rhizostomes; the RRs of epi-benthic C. xamachana medusae were lower than other species in the suborder (Fig. 4). In contrast, confinement of a small hydromedusan species caused increased activity and elevated RRs (Leonard, 1983). We suggest experiments to explicitly test the effects of container size on activity and RRs of medusae.

\section{Minimum rates measured}

A weakness of using metabolic rates to estimate ingestion is that requirements for growth and reproduction and losses to respiration are not included and thus underestimate ingestion. Occasionally, growth has been measured in conjunction with RR experiments, in which maximum specific growth rates of ephyrae were $0.2 \mathrm{~d}^{-1}$ (Olesen et al., 1994; Møller \& Riisgård, 2007). Growth would depend on food availability and be time and location specific. For example, in situ growth rates of Aurelia spp. were about 7\% WW d ${ }^{-1}$ (Schneider, 1989; Omori et al., 1995; Lucas, 1996; Uye \& Shimauchi, 2005), but maximal growth of C. quinquecirrha was $60 \%$ diameter $\mathrm{d}^{-1}\left(\sim 300 \% \mathrm{WW} \mathrm{d}^{-1}\right.$; Olesen et al., 1996). The higher the growth and reproduction rates, the more the SRR regression would underestimate actual ingestion. Increasing daily metabolic rates over basal rates to account for growth in ingestion estimates would be appropriate.

The variation of data used in the SRR regression is greater than in individual studies because of a combination of the above experimental effects. We hopefully minimized the effects of altered temperatures and varied food conditions by selecting studies at ambient temperatures without added food. Medusae in the various studies experienced different collection and experimental protocols, such as light regime and seawater filtration, which may have affected the results but could not be addressed.

Although we believe, for the above reasons, that the RRs probably were lower than those of freeswimming medusae, especially for large specimens and vigorous swimmers like rhizostomes, we believe that use of the SRR is a reasonable approach for estimating RRs and minimum ingestion of scyphomedusae. The coefficient of variation $(72 \%)$ of the predictive SRR regression is a low level of variation, given the extreme variation associated with field sampling. Scyphomedusae are renowned for having inhomogeneous distributions (reviewed in Graham et al., 2001); for example, aerial counts of Rhizostoma octopus ranged over three-orders of magnitude (Houghton et al., 2006). For all of the above reasons, the SRR regression should be considered to give a conservative estimate of RRs.

\section{Methods to measure field metabolic rates}

Due to many possible experimental effects on large, active jellyfish, a method that minimizes confinement effects would be ideal. Many of the blooms of jellyfish around the globe are of very large species, for example $N$. nomurai in Asian waters (up to $\sim 200 \mathrm{~kg}$; Kawahara et al., 2006; Uye, 2008) and $R$. octopus in the Irish Sea (up to $40 \mathrm{~kg}$; Houghton et al., 2007) that are extremely difficult to study because of their great size. Incubation containers to accommodate these jellyfish and maintain a minimum favorable $\mathrm{CV}$ :WW ratio $>50$ should be at least 10 and $2 \mathrm{~m}^{3}$, respectively. The SRR regression enables estimation of such unwieldy jellyfish; however, the rates used to develop the regression suffer from the above confinement problems. An even better approach would be to eliminate container effects.

Effects of confinement on vertebrate RRs inspired development of the doubly labeled water method 
(DLW) to measure the field metabolic rates (FMRs; reviewed in Nagy et al., 1999; Nagy, 2005). DLW has been extensively used on terrestrial species and some marine vertebrates such as sea turtles and pinnipeds; however, the technique can be compromised by high water turnover rates for marine species (Jones et al., 2009) and so probably would be inappropriate for jellyfish. The DLW method is expensive and requires re-capture of the animals for final measurements.

Other methods to measure oxygen consumption are biochemical methods, which involve the determination of the activity of various enzymatic systems, including succinate dehydrogenase, electron transfer system (ETS), lactate dehydrogenase, pyruvate kinase, and citrate synthase (Hernández-León \& Ikeda, 2005). Of those indices, ETS activity has been employed most extensively on marine zooplankton (ICES, 2000). The ETS activity is the capacity of a living system to consume oxygen or another electron acceptor and equates respiratory enzyme activity of the ETS with potential oxygen demand (Packard, 1971). The ratio of RR to ETS reflects the fraction of the respiratory capacity that the organism is using (Packard, 1985). The in vivo RR:ETS ratios of marine zooplankton ranged from 0.5 to 1.0 , the upper range represented by well-fed specimens (HernándezLeón \& Ikeda, 2005). Specifically, RR:ETS ratios measured for 5 hydromedusa species, 1 ctenophore, and semi-gelatinous taxa showed that the ratios were about half those of crustacean zooplankton (Owens \& King, 1975; King \& Packard, 1975; Båmstedt, 2000), presumably because of the high water contents of the gelatinous species.

The ETS method provides good estimates of RRs by the addition of saturated substrate concentrations (Packard, 1971, 1985, Packard \& Gómez, 2008). In nature, the cells of organisms may be substratelimited; therefore, extrapolation of enzyme activities in vitro to those in vivo is not straightforward. In general, ETS measurements reflect the maximum potential oxygen consumption. To closely relate in vitro to in vivo rates, Båmstedt (2000) modified the assay to avoid the addition of substrates and obtained a linear relationship between RR and ETS. Both Packard's and Båmstedt's approaches require calibration of the ETS activity with RRs for each species. Enzyme activity should be standardized by WW (references in Rutherford \& Thuesen, 2005). Packard's ETS method requires use of some hazardous chemicals; however, Båmstedt's modification made the method "simple and well suited for field work". Unlike measurements made according to Packard's method, measurements based on Båmstedt's method should be interpreted carefully because it does not measure the potential respiration activity (Packard, personal communication). Application of the ETS method to medusae in nature would minimize the above problems with laboratory RR experiments and enable estimation of the energetic requirements of even the largest species that present the greatest logistic challenges.

\section{Calculation of ingestion from respiration rates}

Respiration and excretion are basic physiological processes that are related to body mass, temperature, and activity for all animals. They have been used to estimate the minimum food requirements and ingestion for some gelatinous species (e.g., Ishii \& Tanaka, 2006). Because RRs of the scyphozoan species for which respiration data are available are predictable by one equation, it will be easy to estimate minimum energy requirements for scyphomedusae with just data on their size. Ultimately, size data should be in carbon. Size data in the field can be collected as bell diameter if conversions to WW and $\mathrm{C}$ are available.

The RRs for medusae and ctenophores can be used to estimate minimum predation rates (e.g., Ishii \& Tanaka, 2006). The minimum daily carbon ingestion (MDCI) can be calculated by multiplying the daily $\mathrm{RR}$ by the respiratory quotient $(\mathrm{RQ}=0.8)$. The MDCI can be converted to numbers of prey ingested from prey carbon mass when the prey types are known (e.g., ICES, 2000). Thus, population estimates of amounts of prey consumed by gelatinous species in situ can be made from the respiration or excretion rate at the mean jellyfish mass, times the jellyfish population density. The effects on the prey populations can be estimated from prey consumption divided by prey densities in situ, in combination with the field data on predator mass and density, prey mass and densities, and temperature. When growth and ingestion rates are relatively low, respiration will approximately equal ingestion and application of the SRR regression to jellyfish population biomass can approximate ingestion and effects of jellyfish on prey populations. 


\section{Conclusions}

The SRR regression ( $\mathrm{RR}$ in $\mathrm{ml} \quad \mathrm{O}_{2} \quad \mathrm{~d}^{-1}=$ $83.37 * \mathrm{~g} \mathrm{C}^{0.940}$ ) would allow estimation of RRs and minimum energy demands of scyphomedusae $\pm 72 \%$ from data only on jellyfish mass. Although this method is approximate and should be considered conservative, it is important that gelatinous species be included in ecosystem studies and models that now are conducted on regional to global scales (Pauly et al., 2009). This method offers an alternative to when limited resources and time do not permit exhaustive collection of data on jellyfish ingestion. Use of RRs by species, if available, is preferable to use of the SRR regression.

We briefly summarize recommendations for methods to measure metabolic rates for estimation of ingestion in jellyfish:

- Determine jellyfish densities and sizes, including wet and carbon mass, of each species.

- Report temperature and salinity.

- Use ambient temperature for all experiments.

- Conduct metabolic experiments on newly collected specimens for rates that reflect natural food conditions.

- Incubate jellyfish in volumes at least 100-times greater than the wet mass.

- Do not convert metabolic rates by use of $\mathrm{Q}_{10}$ values measured at experimentally manipulated temperatures.

- Calibrate the electron transport system (ETS) method versus RRs to measure field metabolic rates of jellyfish.

- Develop algorithms among taxa that can be used to predict jellyfish effects on large scales.

Acknowledgments This project resulted from a collaboration between the Medusa Project and EcoJel. The Medusa Project was financed by the Agencia Catalana del Agua. EcoJel is a component project of the Interreg 4a IrishWales programme, which forms part of the European Regional Development Fund (ERDF). We thank Drs. A. Malej and Gimenez for hosting D. Astorga (funded by P07-RNM-02976) at the Marine Biology Station and Universidad de Alicante, respectively, and Dr. L. Prieto at CSIC at Andalucía for her assistance. Thanks also to Dr. R. M. Callaway for German translation and Dr. P. Kremer and two anonymous reviewers for their constructive comments on the manuscript.

Open Access This article is distributed under the terms of the Creative Commons Attribution Noncommercial License which permits any noncommercial use, distribution, and reproduction in any medium, provided the original author(s) and source are credited.

\section{References}

Båmstedt, U., 2000. A new method to estimate respiration rate of biological material based on the reduction of tetrazolium violet. Journal of Experimental Marine Biology and Ecology 251: 239-263.

D’Ambra, I., J. H. Costello \& F. Bentivegna, 2001. Flow and prey capture by the scyphomedusa Phyllorhiza punctata von Lendenfeld, 1884. Hydrobiologia 451(Developments in Hydrobiology 155): 223-227.

Dawson, M. N. \& L. E. Martin, 2001. Geographic variation and ecological adaptation in Aurelia (Scyphozoa, Semaeostomeae): some implications from molecular phylogenetics. Hydrobiologia 451(Developments in Hydrobiology 155): 259-273.

Doyle, T. K., J. D. R. Houghton, R. McDevitt, J. Davenport \& G. C. Hays, 2007. The energy density of jellyfish: Estimates from bomb-calorimetry and proximate-composition. Journal of Experimental Marine Biology and Ecology 242: 239-252.

Frandsen, K. T. \& H. U. Riisgård, 1997. Size dependent respiration and growth of jellyfish, Aurelia aurita. Sarsia 82: 307-312.

Glazier, D. S., 2006. The 3/4-power law is not universal: evolution of isometric, ontogenetic metabolic scaling in pelagic animals. BioScience 56: 325-332.

Gordon, M. R. \& J. E. Seymour, 2009. Quantifying movement of the tropical Australian cubozoan Chironex fleckeri using acoustic telemetry. Hydrobiologia 616: 87-97.

Graham, W. M., F. Pagès \& W. M. Hamner, 2001. A physical context for gelatinous zooplankton aggregations: a review. Hydrobiologia 451: 199-212.

Graham, W. M., D. L. Martin, D. L. Felder, V. L. Asper \& H. M. Perry, 2003. Ecological and economic implications of the tropical jellyfish invader, Phyllorhiza punctata von Lendenfeld, in the northern Gulf of Mexico. Biological Invasions 5: 53-69.

Hernández-León, S. \& T. Ikeda, 2005. Zooplankton respiration. In Del Giorgio, P. \& P. J. Williams (eds), Respiration in Aquatic Systems. Oxford University Press, New York: 57-82.

Hirst, A. G. \& C. H. Lucas, 1998. Salinity influences body weight quantification in the scyphomedusa Aurelia aurita: important implication for body weight determination in gelatinous zooplankton. Marine Ecology Progress Series 165: 259-269.

Houghton, J. D. R., T. K. Doyle, M. W. Wilson, J. Davenport \& G. C. Hays, 2006. Jellyfish aggregations and leatherback turtle foraging patterns in a temperate coastal environment. Ecology 87: 1967-1972.

Houghton, J. D. R., T. K. Doyle, M. W. Wilson, J. Davenport \& G. C. Hays, 2007. Stranding events provide indirect insights into the seasonality and persistence of jellyfish medusae (Cnidaria: Scyphozoa). Hydrobiologia 589: $1-13$. 
ICES, 2000. ICES Zooplankton Methodology Manual. Academic Press, London: 705 pp.

Ishii, H. \& F. Tanaka, 2006. Respiration rates and metabolic demands of Aurelia aurita in Tokyo Bay with special reference to large medusae. Plankton and Benthos Research 1: 64-67.

Jones, T. T., M. Hastings, B. L. Bostrom, R. D. Andrews \& D. R. Jones, 2009. Validation of the use of doubly labeled water in the green turtle (Chelonia mydas): a word of caution. Journal of Experimental Biology 212: 26352644.

Kawahara, M., S. Uye, K. Ohtsu \& H. Iizumi, 2006. Unusual population explosion of the giant jellyfish Nemopilema nomurai (Scyphozoa: Rhizostomeae) in East Asian waters. Marine Ecology Progress Series 307: 161-173.

King, F. D. \& T. T. Packard, 1975. Respiration and the activity of the respiratory electron transport system in marine zooplankton. Limnology and Oceanography 20: 849-854.

Kinoshita, J., J. Hiromi \& S. Kadota, 1997. Do respiratory metabolic rates of the scyphomedusa Aurelia aurita scale isometrically throughout ontogeny in a sexual generation? Hydrobiologia 347: 51-55.

Klevjer, T. A., S. Kaartvedt \& U. Båmstedt, 2009. In situ behaviour and acoustic properties of the deep living jellyfish Periphylla periphylla. Journal of Plankton Research 31: 793-803.

Kremer, P., J. Costello, J. Kremer \& M. Canino, 1990. Significance of photosynthetic endosymbionts to the carbon budget of the scyphomedusa Linuche unguiculata. Limnology and Oceanography 35: 609-624.

Krüger, F., 1968. Stoffwechsel und Wachstum bei Scyphomedusan. Helgoländer wissensaftliche Meeresuntersungen 18: 367-383.

Larson, R. J., 1986. Water content, organic content, and carbon and nitrogen composition of medusae from the northeast Pacific. Journal of Experimental Marine Biology and Ecology 99: 107-120.

Larson, R. J., 1987. Respiration and carbon turnover rates of medusae from the NE Pacific. Comparative Biochemistry and Physiology 87A: 93-100.

Larson, R. J., 1991. Diet, prey selection and daily ration of Stomolophus meleagris, a filter-feeding scyphomedusa from the NE Gulf of Mexico. Estuarine and Coastal Shelf Science 32: 511-525.

Larson, R. J., 1992. Riding Langmuir circulations and swimming in circles: A novel form of clustering behavior by the scyphomedusa Linuche unguiculata. Marine Biology 112: 229-235.

Leonard, J. L., 1983. The effect of environmental factors on swimming activity in Sarsia tubulosa M. Sars (Hydrozoa). Marine Behaviour and Physiology 9: 99-110.

Lucas, C. H., 1996. Population dynamics of Aurelia aurita (Scyphozoa) from an isolated brackish lake, with particular reference to sexual reproduction. Journal of Plankton Research 18: 987-1007.

Mangum, C. P., M. J. Oakes \& J. M. Shick, 1972. Rate-temperature responses in scyphozoan medusae and polyps. Marine Biology 15: 298-303.

McCloskey, L. R., L. D. Aamodt \& W. D. Hazelton, 1985. A computer-controlled respirometer for monitoring production and respiration of symbiotic organisms in situ. In
Gabrié, C., et al. (eds), Proceedings of the 5th International Coral Reef Congress 6. Antenne Museum-EPME, Moorea, French Polynesia: 137-142.

McCloskey, L. R., L. Muscatine \& F. P. Wilkerson, 1994. Daily photosynthesis, respiration and carbon budgets in a tropical marine jellyfish (Mastigias sp.). Marine Biology 119: 13-22.

Møller, L. F. \& H. U. Riisgård, 2007. Respiration in the scyphozoan jellyfish Aurelia aurita and two hydromedusae (Sarsia tubulosa and Aequorea vitrina): effect of size, temperature and growth. Marine Ecology Progress Series 330: 149-154.

Morand, P., C. Carré \& D. C. Biggs, 1987. Feeding and metabolism of the jellyfish Pelagia noctiluca (Scyphomedusae, Semaeostomae). Journal of Plankton Research 9: 651-665.

Nagy, K. A., 2005. Field metabolic rate and body size. Journal of Experimental Biology 208: 1621-1625.

Nagy, K. A., I. A. Girard \& T. K. Brown, 1999. Energetics of free-ranging mammals, reptiles, and birds. Annual Review of Nutrition 19: 247-277.

Nemazie, D. A., J. E. Purcell \& P. M. Glibert, 1993. Ammonium excretion by gelatinous zooplankton and their contribution to the ammonium requirements of microplankton in Chesapeake Bay. Marine Biology 116: 451-458.

Olesen, N. J., K. Frandsen \& H. U. Riisgård, 1994. Population dynamics, growth and energetics of jellyfish Aurelia aurita in a shallow fjord. Marine Ecology Progress Series 105: 9-18.

Olesen, N. J., J. E. Purcell \& D. K. Stoecker, 1996. Feeding and growth by ephyrae of scyphomedusae Chrysaora quinquecirrha. Marine Ecology Progress Series 137: 149-159.

Omori, M., H. Ishii \& A. Fujinaga, 1995. Life history strategy of Aurelia aurita (Cnidaria, Scyphomedusae) and its impact on the zooplankton community of Tokyo Bay. ICES Journal of Marine Science 52: 597-603.

Owens, T. G. \& F. D. King, 1975. The measurement of respiratory electron-transport activity in marine zooplankton. Marine Biology 30: 27-36.

Packard, T. T., 1971. The measurement of respiratory electron transport activity in marine phytoplankton. Journal of Marine Research 29: 235-244.

Packard, T. T., 1985. Measurements of electron transport activity of marine microplankton. In Williams, P. J. \& H. W. Jannasch (eds), Advances in Aquatic Microbiology. Academic Press, New York: 207-261.

Packard, T. T. \& M. Gómez, 2008. Exploring a first-principlesbased model for zooplankton respiration. ICES Journal of Marine Science. doi:10.1093/icesjms/fsn003.

Pauly, D., W. M. Graham, S. Libralato, L. Morissette \& M. L. D. Palomares, 2009. Jellyfish in ecosystems, online databases, and ecosystem models. Hydrobiologia 616: 67-85.

Pitt, K. A., K. Koop \& D. Rissik, 2005. Contrasting contributions to inorganic nutrient recycling by the co-occurring jellyfishes, Catostylus mosaicus and Phyllorhiza punctata (Scyphozoa, Rhizostomeae). Journal of Experimental Marine Biology and Ecology 315: 71-86.

Purcell, J. E., 1992. Effects of predation by the scyphomedusan Chrysaora quinquecirrha on zooplankton populations in Chesapeake Bay. Marine Ecology Progress Series 87: 65-76.

Purcell, J. E., 1997. Pelagic cnidarians and ctenophores as predators: selective predation, feeding rates and effects on 
prey populations. Annales de l'Institut océanographique, Paris 73: 125-137.

Purcell, J. E., 2009. Extension of methods for jellyfish and ctenophore trophic ecology to large-scale research. Hydrobiologia 616: 23-50.

Purcell, J. E. \& P. Kremer, 1983. Feeding and metabolism of the siphonophore Sphaeronectes gracilis. Journal of Plankton Research 5: 95-106.

Purcell, J. E., S.-I. Uye \& W.-T. Lo, 2007. Anthropogenic causes of jellyfish blooms and direct consequences for humans: a review. Marine Ecology Progress Series 350: 153-174.

Rutherford, L. D. Jr., \& E. V. Thuesen, 2005. Metabolic performance and survival of medusae in estuarine hypoxia. Marine Ecology Progress Series 294: 189-200.

Schneider, G., 1988. Chemische Zusarnrnensetzung und Biomasseparameter der Ohrenqualle Aurelia aurita. Helgolander Meeresuntersungen 42: 319-327.

Schneider, G., 1989. A comparison of carbon based ammonia excretion rates between gelatinous and non-gelatinous zooplankton: implications and consequences. Marine Biology 106: 219-225.

Shenker, J. M., 1985. Carbon content of the neritic scyphomedusa Chrysaora fuscescens. Journal of Plankton Research 7: 169-173.
Strickland, J. D. H. \& T. R. Parsons, 1972. A practical handbook of seawater analysis. Fisheries Research Board Canada, Bulletin 167: 311 pp.

Suchman, C. L., E. A. Daly, J. E. Keister, W. T. Peterson \& R. D. Brodeur, 2008. Feeding patterns and predation potential of scyphomedusae in a highly productive upwelling region. Marine Ecology Progress Series 358: 161-172.

Uye, S., 2008. Blooms of the giant jellyfish Nemopilema nomurai: a threat to the fisheries sustainability of the East Asian Marginal Seas. Plankton and Benthos Research 3: 125-131.

Uye, S. \& H. Shimauchi, 2005. Population biomass, feeding, respiration and growth rates, and carbon budget of the scyphomedusa Aurelia aurita in the Inland Sea of Japan. Journal of Plankton Research 27: 237-248.

Verde, E. A. \& L. R. McCloskey, 1998. Production, respiration, and photophysiology of the mangrove jellyfish Cassiopea xamachana symbiotic with zooxanthellae: effect of jellyfish size and season. Marine Ecology Progress Series 168: 147-162.

Youngbluth, M. J. \& U. Båmstedt, 2001. Distribution, abundance, behavior and metabolism of Periphylla periphylla, a mesopelagic coronate medusa in a Norwegian fjord. Hydrobiologia 451: 321-333. 